\title{
The diagnostic accuracy of MRI in determining the relations between paraclinoid aneurysms and the cavernous sinus
}

\author{
Sérgio Tadeu Fernandes ${ }^{1} \cdot$ Hugo Leonardo Doria-Netto ${ }^{1} \cdot$ Raphael Vicente Alves $^{1} \cdot$ Renan Luiz Lapate ${ }^{1}$. \\ Nelson Paes Fortes Diniz Ferreira ${ }^{2,3} \cdot$ Manoel Jacobsen Teixeira ${ }^{4}$. Davi Jorge Fontoura Solla ${ }^{4}$. Vitor Nagai Yamaki ${ }^{4}$. \\ Eberval Gadelha Figueiredo ${ }^{4}$
}

Received: 16 September 2021 / Accepted: 17 November 2021 / Published online: 25 November 2021

(c) The Author(s) 2021

\begin{abstract}
Purpose The location of paraclinoid aneurysms is determinant for evaluation of its intradural compartment and risk of SAH after rupture. Advanced MRI techniques have provided clear visualization of the distal dural ring (DDR) to determine whether an aneurysm is intracavernous, transitional or intradural for decision-making. We analyzed the diagnostic accuracy of MRI in predicting whether a paraclinoid aneurysm is intracavernous, transitional or intradural.

Methods We conducted a prospective cohort between January 2014 and December 2018. Patients with paraclinoid aneurysms underwent 3D fast spin-echo MRI sequence before surgical treatment. The DDR was the landmark for MRI characterization of the aneurysms as follow: (i) Intradural; (ii) Transitional; and (iii) Intracavernous. The MRI sensitivity, specificity, positive and negative likelihood ratios were determined compared to the intraoperative findings. We also evaluated the intertechnique agreement using the Cohen's kappa coefficient ( $\kappa$ ) for dichotomous classifications (cavernous vs non-cavernous).

Results Twenty patients were included in the cohort. The accuracy of MRI showed a sensitivity of 86.7\% (95\%CI:59.5-98.3) and specificity of $90.0 \%$ (95\%CI:55.5-99.8). Analyzing only patients without history of SAH, accuracy test improved with a

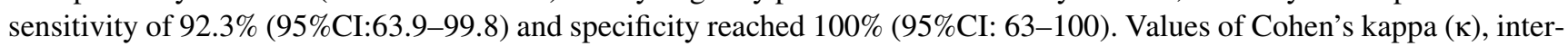
technique agreement was considered substantial for dichotomous classifications $(\kappa=0.754 ; p<0.001)$. For patients without previous SAH, intertechnique agreement was even more coincident for the dichotomous classification $(\kappa=0.901 ; p<0.001)$. Conclusion 3D fast spin-echo MRI sequence is a reliable and useful technique for determining the location of paraclinoid aneurysms in relation to the cavernous sinus, particularly for patients with no history of SAH.
\end{abstract}

Keywords Differential diagnosis $\cdot$ Internal carotid artery $\cdot$ Intertechnique agreement $\cdot$ Intracranial aneurysms ·

Subarachnoid hemorrhage

Sérgio Tadeu Fernandes

s_tadeu@outlook.com

1 Divisão de Neurocirurgia Vascular, Hospital de Transplantes Do Estado de São Paulo Euryclides de Jesus Zerbini, Av. Brigadeiro Luiz Antônio 2651, São Paulo, SP, Brazil

2 Setor de Exames Diagnósticos, Hospital Do Coração, Paraíso, São Paulo, SP, Brazil

3 Alta Excelência Diagnóstica, Ibirapuera, São Paulo, SP, Brazil

4 Departamento de Neurologia, Divisão de Neurocirugia, Faculdade de Medicina, Universidade de São Paulo, São Paulo, SP, Brazil

\section{Introduction}

Cerebral aneurysms located in the intradural compartment are at higher risk of rupture and often require endovascular/microsurgical treatment. In contrast, aneurysms located within the cavernous sinus rarely manifest with SAH and have lower morbidity and mortality. Unfortunately, brainimaging techniques generally do not disclose whether the clinoid segment (C5) is intracavernous or non-cavernous [1-12]. Hence, it is not always possible to achieve an accurate topographic diagnosis of brain aneurysms located in this segment of the ICA regarding their relationship with the carotid collar, the proximal dural ring (PDR) and the distal dural ring (DDR), or to determine if the aneurysm is intracavernous, transitional or intradural [9, 13-18]. 
Several studies have suggested that complementary MRI is effective in predicting the location of paraclinoid aneurysms $[11,13,15,16,18,19]$. However, most studies have not provided sufficient evidence regarding the agreement between MRI and intraoperative findings. On this basis, we analyzed the diagnostic accuracy of MRI in predicting whether a paraclinoid aneurysm is intracavernous, transitional or intradural.

\section{Material and methods}

\section{Study design}

This is a cohort comprising individuals recruited between January/2014 and December/2018. The study was approved by the Institutional Review Board (protocol no. 456.498-10/03/2103). Informed consent form was assigned for all participants.

\section{Study population}

The minimum sample size required to achieve the $95 \%$ confidence level $(95 \% \mathrm{CI})$ was determined to be 16 according to the following equation:

$$
\begin{aligned}
& \text { Sample size }(\mathrm{n})=[\mathrm{DEFF} * \mathrm{~Np}(1-\mathrm{p})] \\
& /[(\mathrm{d} 2 / \mathrm{Z} 21-\alpha / 2 *(\mathrm{~N}-1)+p *(1-\mathrm{p})]
\end{aligned}
$$

\section{DEFF design effect (taken as 1.0 for random sampling) $\mathrm{N}$ sample size \\ $\mathrm{p} \quad$ assumed hypothetical frequency of aneurysms in the population (1\%) \\ d desired absolute precision (0.05) \\ $\mathrm{Z} \quad$ critical value for $95 \% \mathrm{CI}$.}

The inclusion criteria were: (i) the presence of multiple aneurysms with at least one classified as paraclinoid; or (ii) the presence of a single paraclinoid aneurysm. The exclusion criteria were: (i) MRI contraindications; (ii) contraindications for microsurgical treatment; (iii) presence of a single aneurysm unambiguously classified as intracavernous without previous $\mathrm{SAH}$; and (iv) pregnancy. Of note: (i) the primary objective of all procedures was the decision to treat and planning of microsurgical clipping of paraclinoid aneurysms; (ii) the authors understand the current practice preferentially recommends the endovascular approach for paraclinoid aneurysms. However, the Brazilian public health system does not routinely afford flow diverter devices, providing a window of opportunity to investigate this issue, which is relevant regardless of the treatment method.

\section{Acquisition of MRI data}

Coronal T2-weighted images were acquired on a MAGNETOM ${ }^{\circledR}$ Verio 3 Tesla (3 T) MRI scanner (Siemens, Erlangen/Germany) with an 8-channel head coil using a 3D fast spin-echo sequence. The spatial matrix was obtained using the sensitivity encoding technique with the parameters set as follows: repetition time, $4700-6550 \mathrm{~ms}$; echo time, 104.6-110.6 ms; field-of-view, $18-20 \times 18-20 \mathrm{~cm}$; slice thickness, $2 \mathrm{~mm}$, space/gap, $0 \mathrm{~mm}$; matrix size, $448 \times 448$, number of excitations, 4; echo train length, 17.

Images were analyzed by a single neuroradiologist with more than 20 years of experience in order to identify the PDR, the DDR and adjacent anatomical landmarks, the paraclinoid aneurysm and the relationship of the neck and dome of the aneurysm with adjacent structures. The DDR was the landmark for MRI characterization. It was identified as the reflection of the dura mater that surrounds the ICA at the point of exit from the cavernous sinus roof [3, 4, 16-18].

The positions of paraclinoid aneurysms in relation to the DDR were classified as follows: (i) intradural — both neck and dome located distally to the DDR; (ii) transitional — neck or dome (but not both) located distally to the DDR; and (iii) intracavernous (extradural) - both neck and dome located proximally to the DDR $[9,14,16,18,20]$. Aneurysms were further classified based on the spatial orientation of the dome in relation to the roof of the cavernous sinus as superior, medial, lateral or inferior as previously described by Krisht and Hsu [21].

\section{Microsurgical procedure}

The patient was placed in a horizontal supine position with the head turned contralaterally for a pterional craniotomy. Microscopic dissection exposed the sphenoidal segment of the middle cerebral artery, the proximal segment of the anterior cerebral artery and the entire ICA supraclinoid segment with all the associated cisterns and nerves in order to allow visualization of the dura mater covering the anterior clinoid process (ACP).

Anterior clinoidectomy extended from the medial border of the optic nerve to the lateral margin of the lesser sphenoid wing over the superior orbital fissure and $1 \mathrm{~cm}$ from the posterior margin of the optic canal. The ACP tip was disconnected from the sphenoid and detached from the carotid-oculomotor membrane. Osteotomy of the optic strut was performed when needed and fibrin glue injection was used as necessary to reduce bleeding from the cavernous sinus and allow clinoid triangle clear definition [22, 23].

Patients presenting aneurysms unambiguously intradural or transitional, dissection through the neck proceeded for aneurysms clipping. The surgical procedure was recorded for analysis. 
Table 1 Characteristics of 20 patients of the cohort and of 25 paraclinoid aneurysms studied

\begin{tabular}{|c|c|c|c|c|c|c|c|c|}
\hline \multicolumn{5}{|c|}{ Patients } & \multicolumn{4}{|c|}{ Paraclinoid aneurysms } \\
\hline \multirow[t]{2}{*}{ Code } & \multirow{2}{*}{$\begin{array}{l}\text { Age } \\
\text { (years) }\end{array}$} & \multirow[t]{2}{*}{ Gender } & \multirow{2}{*}{$\begin{array}{l}\text { SAH } \\
\text { history }\end{array}$} & \multirow[t]{2}{*}{ Code } & \multicolumn{2}{|c|}{ Location $^{\mathrm{a}}$} & \multirow{2}{*}{$\begin{array}{l}\text { Size } \\
(\mathrm{mm})\end{array}$} & \multirow{2}{*}{$\begin{array}{l}\text { Spatial } \\
\text { orientation }^{\mathrm{b}}\end{array}$} \\
\hline & & & & & MRI & M & & \\
\hline \multirow[t]{2}{*}{ A } & \multirow[t]{2}{*}{61} & \multirow[t]{2}{*}{ Female } & \multirow[t]{2}{*}{ No } & $\# 1$ & I & I & 8 & M \\
\hline & & & & \#2 & $\mathrm{C}$ & $\mathrm{C}$ & 3 & I \\
\hline B & 52 & Female & Yes & \#3 & $\mathrm{C}$ & $\mathrm{C}$ & 2 & $S$ \\
\hline $\mathrm{C}$ & 41 & Female & No & \#4 & $\mathrm{C}$ & $\mathrm{C}$ & 7 & M \\
\hline $\mathrm{D}$ & 44 & Female & Yes & $\# 5$ & $\mathrm{C}$ & $\mathrm{T}$ & 6 & M \\
\hline $\mathrm{E}$ & 38 & Female & Yes & $\# 6$ & I & $\mathrm{T}$ & 5 & M \\
\hline $\mathrm{F}$ & 65 & Female & No & $\# 7$ & $\mathrm{C}$ & $\mathrm{C}$ & 5 & M \\
\hline \multirow[t]{2}{*}{ G } & \multirow[t]{2}{*}{65} & \multirow[t]{2}{*}{ Female } & \multirow[t]{2}{*}{ No } & \#8 & I & I & 11 & $\mathrm{~L}$ \\
\hline & & & & $\# 9$ & I & I & 5 & $S$ \\
\hline \multirow[t]{2}{*}{$\mathrm{H}$} & \multirow[t]{2}{*}{55} & \multirow[t]{2}{*}{ Female } & \multirow[t]{2}{*}{ No } & $\# 10$ & I & I & 5 & S \\
\hline & & & & $\# 11$ & I & I & 18 & M \\
\hline I & 56 & Female & No & $\# 12$ & I & I & 4 & S \\
\hline $\mathrm{J}$ & 38 & Female & Yes & $\# 13$ & $\mathrm{~T}$ & $\mathrm{C}$ & 5 & M \\
\hline K & 33 & Female & No & $\# 14$ & $\mathrm{C}$ & $\mathrm{C}$ & 3 & $S$ \\
\hline $\mathrm{L}$ & 66 & Female & No & $\# 15$ & I & I & 4 & M \\
\hline \multirow[t]{2}{*}{ M } & \multirow[t]{2}{*}{40} & \multirow[t]{2}{*}{ Female } & \multirow[t]{2}{*}{ No } & $\# 16$ & I & I & 5 & S \\
\hline & & & & \#17 & I & I & 3 & $\mathrm{~L}$ \\
\hline $\mathrm{N}$ & 34 & Female & No & $\# 18$ & $\mathrm{C}$ & $\mathrm{C}$ & 4 & M \\
\hline $\mathrm{O}$ & 47 & Female & No & \#19 & $\mathrm{C}$ & $\mathrm{C}$ & 5 & M \\
\hline $\mathrm{P}$ & 53 & Male & No & $\# 20$ & $\mathrm{C}$ & I & 4 & M \\
\hline \multirow[t]{2}{*}{ Q } & \multirow[t]{2}{*}{49} & \multirow[t]{2}{*}{ Female } & \multirow[t]{2}{*}{ No } & $\# 21$ & I & I & 3 & M \\
\hline & & & & $\# 22$ & I & I & 4 & S \\
\hline $\mathrm{R}$ & 73 & Female & No & \#23 & $\mathrm{C}$ & $\mathrm{C}$ & 6 & M \\
\hline $\mathrm{S}$ & 63 & Female & No & $\# 24$ & I & I & 5 & M \\
\hline $\mathrm{T}$ & 41 & Female & No & $\# 25$ & $\mathrm{C}$ & $\mathrm{C}$ & 5 & M \\
\hline
\end{tabular}

${ }^{a}$ Intracavernous (C), transitional (T) and intradural (I) locations determined by MRI or microsurgery (M)

${ }^{\mathrm{b}}$ Spatial orientations of the dome in relation to the cavernous sinus roof classified according to Krisht and Hsu as superior (S), medial (M), lateral (L) or inferior (I)

\section{Statistical analysis}

Categorical variables were described as absolute and relative frequencies and compared using the $\chi 2$ test. Continuous variables were assessed for normality using graphical methods and skewness/kurtosis statistics. Age was expressed as mean \pm standard deviation and compared using independent samples t-test. Aneurysm sizes were expressed as median and quartiles and compared using the Mann-Whitney test. In order to evaluate the accuracy of MRI screening with respect to the location of paraclinoid aneurysms, taking intraoperative findings as gold standard, a dichotomous classification was adopted. Transitional and intradural locations were merged into the non-cavernous group. Sensitivity, specificity, positive and negative likelihood ratios (PLR and NLR, respectively), and positive and negative predictive values (PPV and NPV) were calculated. The agreement between the results of MRI screening and intraoperative findings was evaluated for both trichotomous (i.e. intracavernous, transitional and intradural) and dichotomous classifications according to Cohen's kappa coefficient ( $\kappa)$ with the following interpretations: 0 (no agreement); $0.10-0.19$ (poor); 0.20-0.39 (fair); 0.40-0.59 (moderate); 0.60-0.79 (substantial); 0.80-0.99 (almost perfect) and 1.00 (perfect). Statistical significance was set at 0.05 and the tests were two-tailed. All analyses were performed with the aid of IBM SPSS software version 24.0 (Armonk/NY/USA) and MedCalc Statistical software version 15.2.0.0 (Ostend/Belgium).

\section{Results}

\section{Characteristics of the sample population}

Twenty-two patients were eligible and 20 ( 1 male and 19 females) were ultimately included. One did not undergo surgery within the study time frame and another was excluded due to MRI acquisition inadequacies. 
Table 2 Characteristics of 20 patients of the cohort and size, location and spatial orientation of 25 paraclinoid aneurysms studied

\begin{tabular}{|c|c|c|c|c|}
\hline \multirow[t]{2}{*}{ Variable } & \multirow[t]{2}{*}{ Value } & \multicolumn{2}{|l|}{ Location of aneurisms $^{\mathrm{a}}$} & \multirow[t]{2}{*}{$P$ value } \\
\hline & & Intracavernous $(n=10)$ & Non-cavernous $(n=15)$ & \\
\hline Age (years); mean \pm standard deviation & $51.4 \pm 11.5$ & $48.5 \pm 13.8$ & $53.3 \pm 9.7$ & $0.313^{\mathrm{b}}$ \\
\hline Number of aneurysms in females (percentage of total) & $24 / 25(96)$ & $10 / 10(100)$ & $14 / 15(93.3)$ & $1.000^{\mathrm{c}}$ \\
\hline Size of aneurysms (mm); median (interquartile range) & $5.0(4.0-5.5)$ & $5.0(3.0-5.3)$ & $5.0(4.0-6.0)$ & $0.511^{\mathrm{d}}$ \\
\hline Spatial orientation ${ }^{\mathrm{e}}$ of aneurysms; number (percentage) & & & & $0.322^{\mathrm{c}}$ \\
\hline Superior & $7 / 25(28)$ & $2 / 10(20)$ & $5 / 15(33.3)$ & \\
\hline Medial & $15 / 25(60)$ & $7 / 10(70)$ & $8 / 15(53.3)$ & \\
\hline Lateral & $2 / 25(8)$ & 0 & $2 / 15(13.3)$ & \\
\hline Inferior & $1 / 25(4)$ & $1 / 10(10)$ & 0 & \\
\hline
\end{tabular}

${ }^{\text {a }}$ Non-cavernous aneurysms comprised the intradural and transitional types

${ }^{\mathrm{b}}$ Not significant according to Student's $t$ test $(p>0.05)$

${ }^{\mathrm{c}}$ Not significant according to $\chi^{2}$ test $(p>0.05)$

${ }^{\mathrm{d}}$ Not significant according to Mann-Whitney test $(p>0.05)$

${ }^{\mathrm{e}}$ Classified as described by Krisht and Hsu

The mean age was $51.4 \pm 11.5$ years. Fifteen $(75 \%)$ participants presented $\geq 2$ aneurysms with five patients having multiple paraclinoid aneurysms. A total of 25 paraclinoid aneurysms were considered individually in the analyses. Table 1 describes the sample.

\section{Characteristics of paraclinoid aneurysms}

The median aneurysm size was $5.0 \mathrm{~mm}$ (range $3-18 \mathrm{~mm}$ ). Patients presenting with intracavernous or non-cavernous aneurysms had similar age $(p=0.313)$. The spatial orientation of the aneurysms in relation to the roof of the cavernous sinus were: $60 \%(15 / 25)$ medial projection, $28 \%(7 / 25)$ superior, 8\% (2/25) lateral, and 4\% (1/25) inferior (Tables 1 and 2).

\section{MRI screening vs. microsurgical findings}

According to intraoperative findings, $40 \%$ (10/25) of the aneurysms were intracavernous, $8 \%(2 / 25)$ transitional and $52 \%(13 / 25)$ intradural, whereas MRI scans indicated $44.4 \%$ $(11 / 25)$ of the aneurysms as intracavernous, $4 \%(1 / 25)$ as transitional and 52\% (13/25) as intradural (Tables 1 and 3 ). Examples of intracavernous, transitional and intradural aneurysms are presented in Figs. 1, 2, 3, 4. Figure 5 presents

Table 3 Level of agreement between MRI and microsurgery regarding the classification of 25 paraclinoid aneurysms studied

Trichotomous classification of aneurysms

MRI

$\kappa=0.709 ; P<0.001$

Dichotomous classification of aneurysms

$\begin{array}{lll} & & \text { Intracavernous } \\ \text { MRI } & \text { Intracavernous } & 9(36) \\ & \text { Non-cavernous } & 1(4) \\ \text { Microsurgery totals } & & 10(40) \\ \kappa=0.754 ; P<0.001 & & \end{array}$

Microsurgery $n(\%)$

Intracavernous Transitional

9 (36)

$1(4)$

Transitional

Intradural

$1(4)$

0

$10(40)$
0

1 (4)

2 (8)
MRI totals

Intradural

$\begin{array}{ll}1(4) & 11(44.4) \\ 0 & 1(4) \\ 12(48) & 13(52) \\ 13(52) & 25(100)\end{array}$

a Non-cavernous aneurysms comprised the intradural and transitional types 

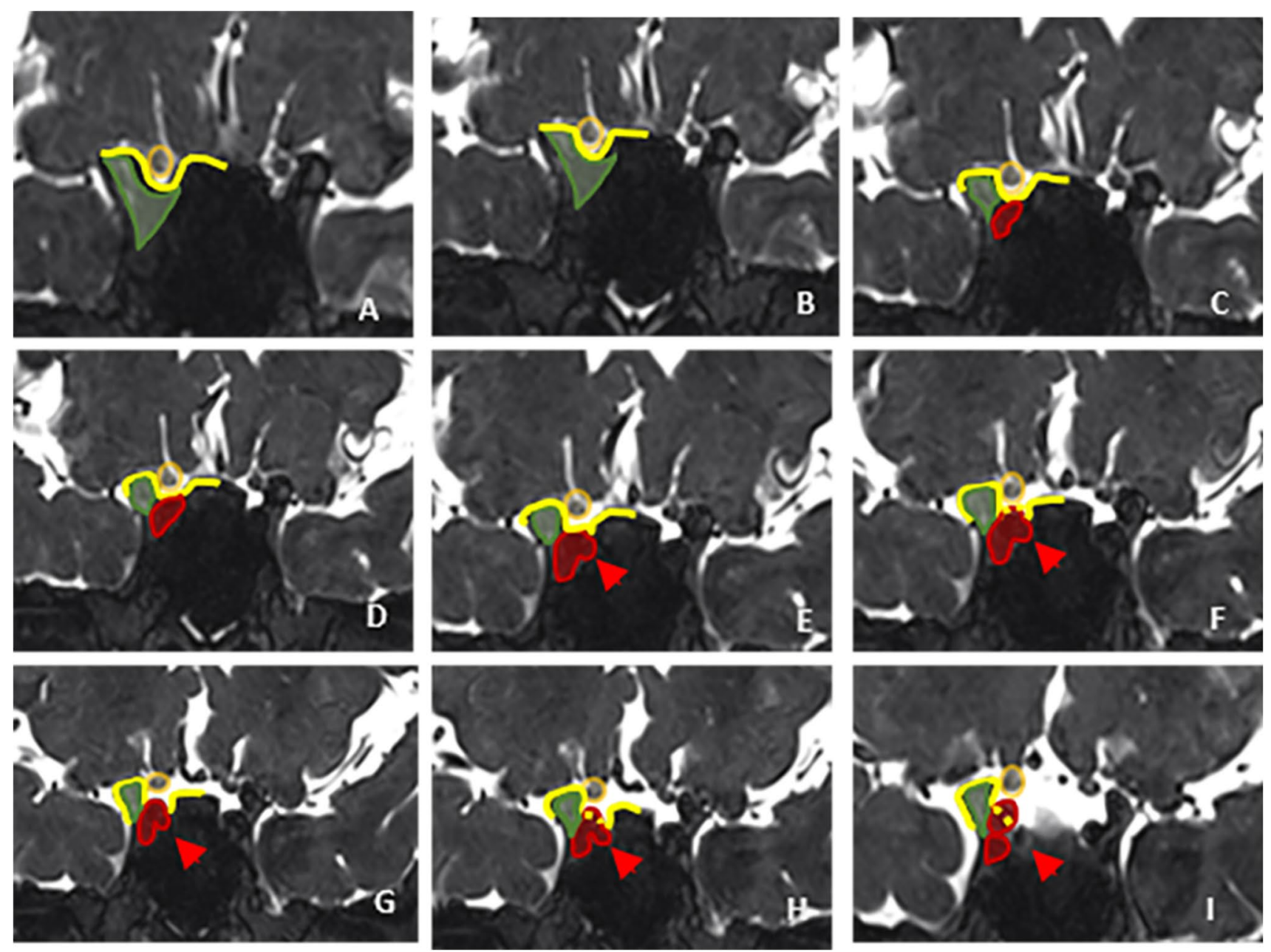

Fig. 1 Coronal T2-weighted magnetic resonance imaging (MRI) scans acquired with a 3D fast spin-echo sequence showing anterior to posterior views of the anatomoradiological markers of the paraclinoid region with the reflection of the dura-mater represented by the yellow line. The anterior clinoid process and optic pillar are identified in green (panels A-I), the optic nerve in gold, the anterior curve of the

a transitional aneurysm previously classified as intracavernous on MRI.

\section{Accuracy of MRI screening and intertechnique agreement}

MRI sensitivity (probability of correctly indicating an aneurysm as non-cavernous) $86.7 \%$ (95\%CI: 59.5-98.3). MRI specificity was $90.0 \%$ (95\%CI: 55.5-99.8). PLR and NLR values were 8.7 (95\%CI: $1.3-56.2)$ and 0.15 (95\%CI: $0.04-0.6)$, respectively. The PPV and NPV values were 92.9\% (95\%CI: 66.1-99.8) and 81.8\% (IC95\%: 48.2-97.7), respectively.

For the subgroup of patients without previous $\mathrm{SAH}$, sensitivity (92.3\%; 95\%CI: 63.9-99.8) and specificity (100\%; 95\%CI: 63-100) increased, while NLR decreased internal carotid artery (ICA) in red (panels $\mathbf{C}-\mathbf{H}$ ), the horizontal segment of the cavernous ICA (panel I) and the aneurysm itself by red arrows (panels $\mathbf{E}-\mathbf{I}$ ). Note that the posterior portion of the transitional aneurysm projects into the subarachnoid space - located above the distal dural ring (interrupted yellow line)

to 0.08 (95\%CI: $0.01-0.51)$. PPV and NPV values reached 100\% (IC95\%: 73.5-100) and 88.9\% (IC95\%: 51.7-99.7), respectively.

The agreement was considered substantial for both dichotomous $(\kappa=0.754 ; p<0.001)$ and trichotomous $(\kappa=0.709 ; p<0.001)$ classifications (Table 3$)$. For the subgroup of patients without previous $\mathrm{SAH}$, agreement was even greater for the dichotomous classification $(\kappa=0.901$; $p<0.001)$.

\section{Illustrative cases}

The findings from MRI and microsurgery disagreed in aneurysms \#5, \#6, \#13, and \#20 (Table 1), all of which were $\leq 6 \mathrm{~mm}$ and medially orientated. Patients \#5, \#6, and \#13 had previous SAH. Aneurysm \#20 was the only one 

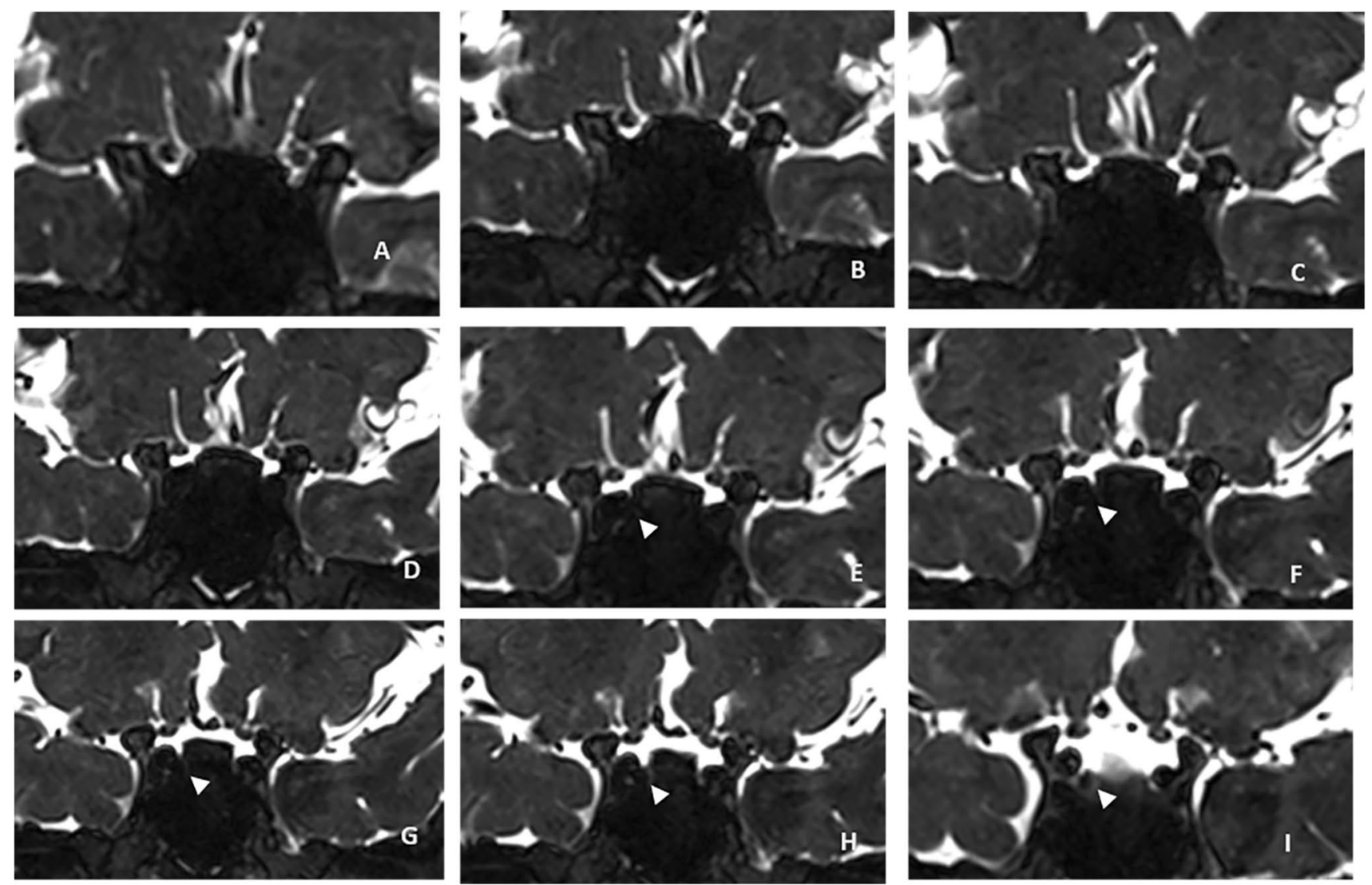

Fig. 2 Coronal T2-weighted magnetic resonance imaging (MRI) scans acquired with a $3 \mathrm{D}$ fast spin-echo sequence showing anterior to posterior views of the anatomoradiological markers of the paraclinoid region as in Fig. 1 except that the markers are not highlighted (panels

without previous $\mathrm{SAH}$, which presented disagreement. Previously classified as intracavernous aneurysm on MRI, the DDR was opened before the location of the aneurysm had been ascertained. The practical translational meaning of our findings is: all patients with transitional or intradural aneurysms, eligible for surgical treatment, would be diagnosed correctly by MRI. Moreover, the calculated PPV of $100 \%$ means that all aneurysms classified as transitional or intradural (non-cavernous) by microsurgery were previously detected by MRI.

\section{Discussion}

The MRI sensitivity was $86.7 \%$ while its specificity was $90 \%$, thus demonstrating reliability for determining the location of paraclinoid aneurysms in relation to the DDR. MRI was efficient in ruling out the occurrence of non-cavernous aneurysms. Therefore, the probability of finding a
A-D). The transitional aneurysm is indicated by white arrow heads (panels E-I). Note that the posterior portion of the transitional aneurysm (black arrow) projects into the subarachnoid space

non-cavernous aneurysm when a radiologist has classified an aneurysm as intracavernous based on MRI imaging is exceedingly small.

Aneurysms with previous SAH presented greater disagreement between the surgical findings and MRI impression. These divergences might be explained by possible arachnoiditis and consequent membranes thickening, or even some anatomical deformation of the paraclinoid region resulting from the SAH-induced inflammatory process. Interestingly, aneurysm \#3 was also associated with a history of SAH from another aneurysm, but with concordant intracavernous location between MRI and surgery. For intracavernous aneurysms, we believe that the inflammatory process triggered by SAH might not influence MRI evaluation because they are not in contact with the subarachnoid space. Nevertheless, once SAH cases were excluded, MRI accuracy improved as well as its agreement with the intraoperative findings.

No studies have focused on the accuracy of diagnostic tests for determining the location of paraclinoid aneurysms in relation to the cavernous sinus. Reports available 
Fig. 3 Cerebral digital subtraction angiography (DSA) of intradural aneurysm \#22 (see Table 1) showing anteroposterior (panel A) and profile (panel B) views. Note the medial and inferior projection of the aneurysm (white arrows). Coronal T2-weighted magnetic resonance imaging (MRI) scans with a 3D fast spin-echo sequence showing anterior to posterior views of the anatomoradiological markers of the paraclinoid region and intradural aneurysm \#22 (panels C-F). Note the hyper-intense signal from the cerebrospinal fluid (white arrows). In panel G-I, three-dimensional time-of-flight (TOF) magnetic resonance angiography was employed to enhance the view of the aneurysm (white arrows)
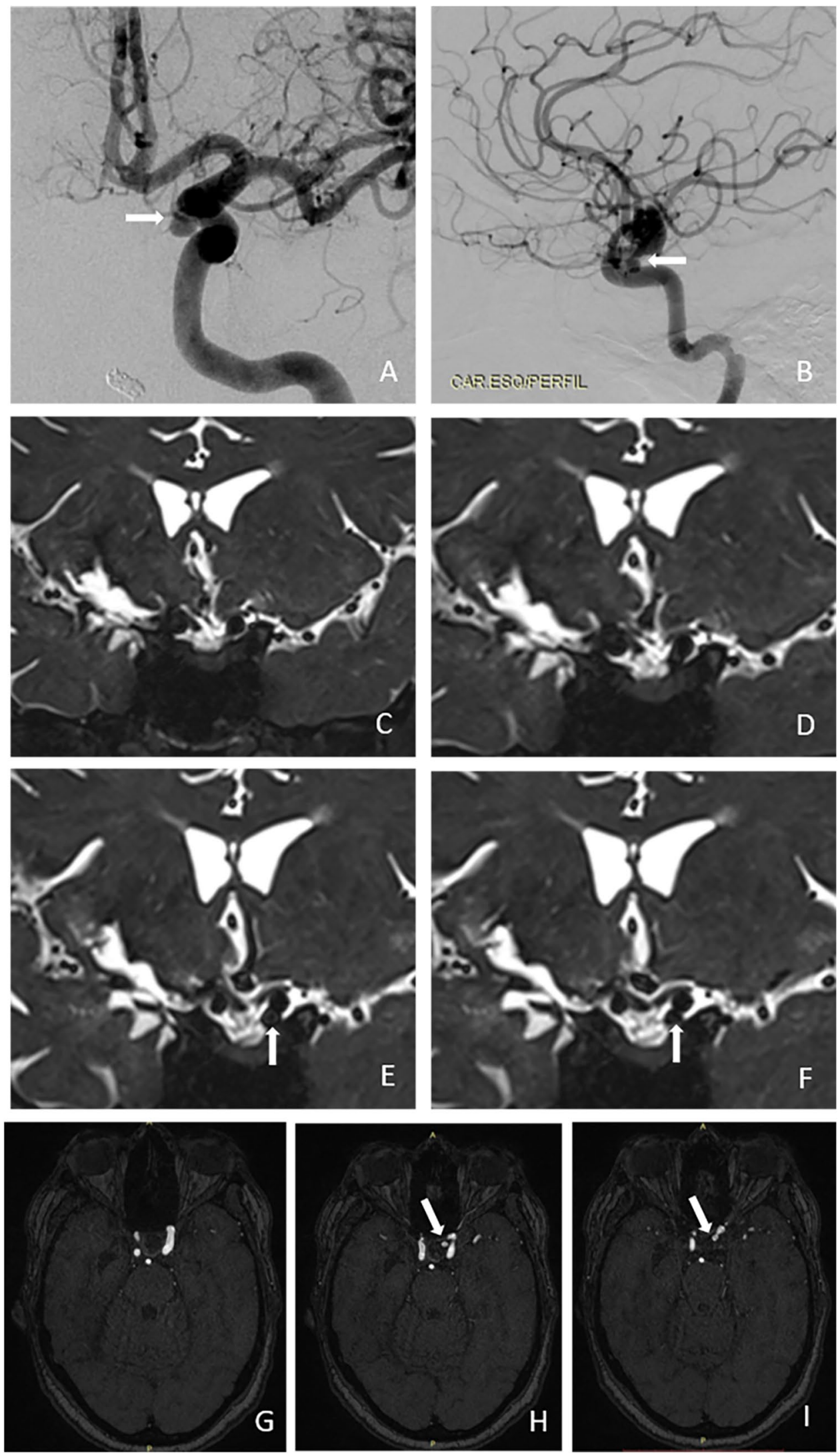
Fig. 4 Cerebral digital subtraction angiography (DSA) of intracavernous aneurysm \#19 (see Table 1) showing anteroposterior (panels $\mathbf{A}$ and $\mathbf{C}$ ) and profile (panels $\mathbf{B}$ and $\mathbf{D}$ ) views. Note the medial projection of the aneurysm (white arrows). Coronal T2-weighted magnetic resonance imaging (MRI) scans with a $3 \mathrm{D}$ fast spin-echo sequence showing anterior to posterior views of the anatomoradiological markers of the paraclinoid region and intracavernous aneurysm \#19 (panels E-H). Note the hyper-intense signal from the cerebrospinal fluid around the distal dural ring and no contact between CSF and the aneurysm (arrow heads)
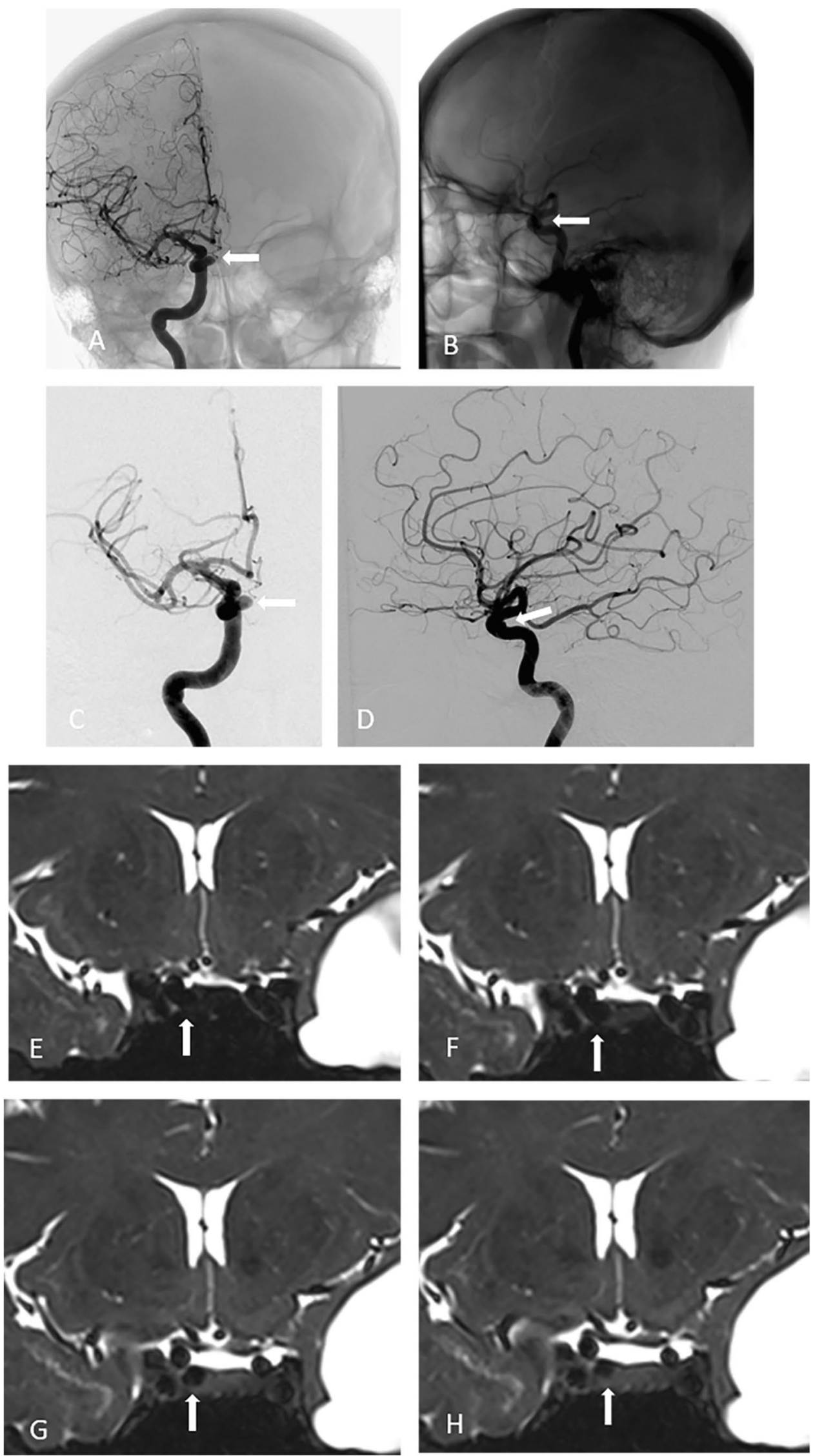
Fig. 5 Cerebral digital subtraction angiography (DSA) of aneurysm \#5 that caused intertechnique disagreement (see Table 1) showing anteroposterior (panel A) and profile (panel B) views. Note the medial projection of the aneurysm (white arrows). The relationship between the aneurysm and bony structures are shown (panels $\mathbf{C}$ and D). Coronal T2-weighted magnetic resonance imaging (MRI) scans with a 3D fast spin-echo sequence showing anterior to posterior views of the anatomoradiological markers of the paraclinoid region and the intracavernous (MRI)/ transitional (M) aneurysm \#5 (panels $\mathbf{G}-\mathbf{J}$; aneurysm white arrows)
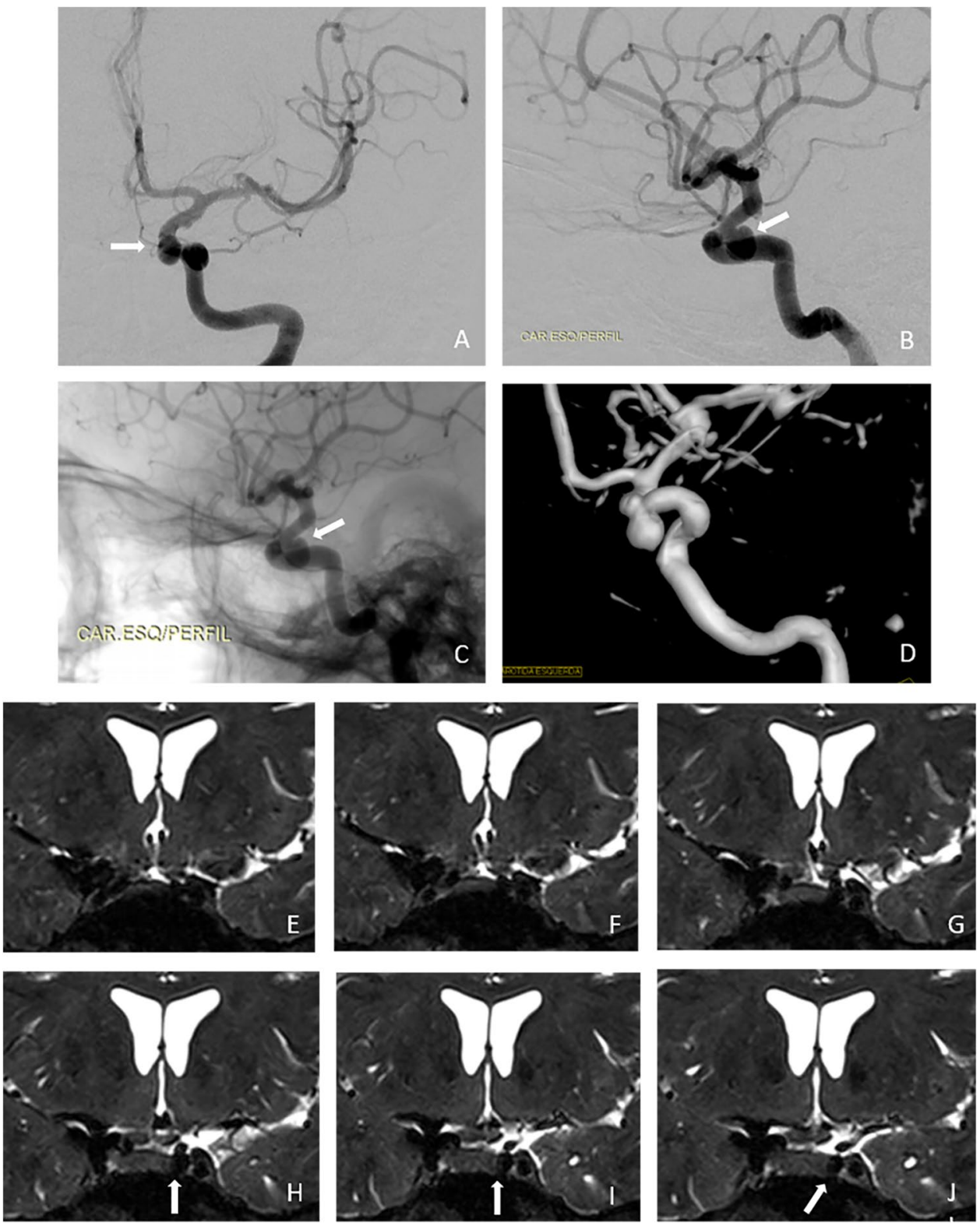

describe case series without sensitivity, specificity, and predictive values analysis $[14,16,18,20,24-28]$. For instance, Thines et al. [20] compared MRI with DSA and reported that MRI permitted the direct visualization of DDR and its relation to paraclinoid aneurysms. However, MRI accuracy compared to surgical findings or post mortem dissections was not reported.

The relationship of the aneurysm with the ophthalmic artery (OA) have been proposed as landmark for distinguishing between intra- and extradural paraclinoid aneurysms. However, the OA has extradural location in 2-8\% of patients which is not reliable [29]. Other methods with $\mathrm{CT}$ angiography have been proposed for the paraclinoid aneurysms study based on bony limits of the DDR. Liao et al. [30] suggested the optic strut (OS) as a reliable landmark to determine an intradural growth of the aneurysm. The DDR is attached to the OS which might represent the anatomical limit between the intradural and extradural compartments. However, the OS represents only the anterior limit of the DDR that is not applied to all paraclinoid aneurysms that rise from different portions of the ICA. Therefore, Scerbak et al. [31] proposed a DDR plane based on four bony landmarks: (1) the intersection between the anterior clinoid and the ICA; (2) optic strut, (3) opticocarotid elevation, and (4) posterior clinoid process. They found $100 \%$ agreement between the radiological impression and surgical findings regarding the extension of the paraclinoid aneurysm in the subarachnoid space; however, 
these methods provide indirect evaluation of the DDR disposition. Our MRI method, on the other hand, provides direct coronal view of the DDR limits and the intradural portion of the aneurysm crossing the DDR limit.

The study described herein has some limitations. Our objective was to assess the accuracy, but not the reproducibility, of preoperative MRI. Since this is a single center study (one neuroradiologist and one neurosurgeon), further confirmation by multicentric studies is required. Although microsurgery was defined as the gold standard method against which MRI was tested, distraction during the surgical procedure could lead to aneurysm misclassification. Despite our status as a referral hospital for brain aneurysm treatment, it took 4 years for sufficient recruitment such that the learning curves for image interpretation and improvement of the microsurgery technique could be refined. The discrepancies observed between the two techniques appeared to be associated with anatomical deformities or MRI distortion caused by SAH-induced inflammation. While the exclusion of aneurysms with a history of SAH improved MRI accuracy, this could represent a potential limiting factor of the technique. Despite these shortcomings, the results of this study are robust and provide foundations for improvement of experimental design in future research.

MRI with 3D fast spin-echo sequence is a reliable and useful technique for determining the location of paraclinoid aneurysms in relation to the cavernous sinus and establishing the most appropriate therapeutic approach particularly for patients with paraclinoid aneurysm and no history of SAH.

Availability of data and material Data is fully available if necessary.

Code availability Not applicable.

\section{Declarations}

\section{Conflict of interest None.}

Ethical approval The study was approved by the Universidade de Sao Paulo's Institutional Review Board (protocol no. 456.498-10/03/2103).

Informed consent Not applicable.

Open Access This article is licensed under a Creative Commons Attribution 4.0 International License, which permits use, sharing, adaptation, distribution and reproduction in any medium or format, as long as you give appropriate credit to the original author(s) and the source, provide a link to the Creative Commons licence, and indicate if changes were made. The images or other third party material in this article are included in the article's Creative Commons licence, unless indicated otherwise in a credit line to the material. If material is not included in the article's Creative Commons licence and your intended use is not permitted by statutory regulation or exceeds the permitted use, you will need to obtain permission directly from the copyright holder. To view a copy of this licence, visit http://creativecommons.org/licenses/by/4.0/.

\section{References}

1. Bouthillier A, Van Loveren HR, Keller JT (1996) Segments of the internal carotid artery: a new classification. Neurosurgery 38:425-433. https://doi.org/10.1097/00006123-199603000-00001

2. Day AL (1990) Aneurysms of the ophthalmic segment. A clinical and anatomical analysis. J Neurosurg 72:677-691. https://doi.org/ 10.3171/jns. 1990.72.5.0677

3. De Jesús O, Sekhar LN, Riedel CJ (1999) Clinoid and paraclinoid aneurysms: surgical anatomy, operative techniques, and outcome. Surg Neurol 51:477-488. https://doi.org/10.1016/S0090-3019(98) 00137-2

4. Seoane E, Rhoton AL, De Oliveira E (1998) Microsurgical anatomy of the dural collar (carotid collar) and rings around the clinoid segment of the internal carotid artery. Neurosurgery 42:869-886. https://doi.org/10.1097/00006123-199804000-00108

5. Dolenc V (1983) Direct microsurgical repair of intracavernous vascular lesions. J Neurosurg 58:824-831. https://doi.org/10. 3171/jns.1983.58.6.0824

6. Dolenc VV (1985) A combined epi- and subdural direct approach to carotid-ophthalmic artery aneurysms. J Neurosurg 62:667-672. https://doi.org/10.3171/jns.1985.62.5.0667

7. Knosp E, Müller G, Neurosurgery AP-, 1988 undefined The paraclinoid carotid artery: anatomical aspects of a microneurosurgical approach. academic.oup.com

8. Lang J, Kageyama I (1990) Clinical anatomy of the blood spaces and blood vessels surrounding the siphon of the internal carotid artery. Acta Anat (Basel) 139:320-325. https://doi.org/10.1159/ 000147019

9. Matsumoto M, Mizutani T, Sugiyama T et al (2019) Distance between the falciform ligament and distal dural ring as a surgical landmark for the treatment of paraclinoid aneurysms. World Neurosurg 124:e498-e502. https://doi.org/10.1016/j.wneu.2018. 12.120

10. Nutik SL (1988) Removal of the anterior clinoid process for exposure of the proximal intracranial carotid artery. J Neurosurg 69:529-534. https://doi.org/10.3171/jns.1988.69.4.0529

11. Perneczky A, Knosp E, Vorkapic P, Czech T (1985) Direct surgical approach to infraclinoidal aneurysms. Acta Neurochir (Wien) 76:36-44. https://doi.org/10.1007/BF01403827

12. Ramalho Romero F, Ramires D, Carrara Cristiano L et al (2017) Endoscopic and microsurgical approaches to the cavernous sinusanatomical review Abordagem endoscópica e microcirúrgica do seio cavernoso-revisão da anatomia. Arq Bras Neurocir 36:160166. https://doi.org/10.1055/s-0037-1604166

13. Al-Rodhan NRF, Piepgras DG, Sundt TM (1993) Transitional cavernous aneurysms of the internal carotid artery. Neurosurgery 33:993-998. https://doi.org/10.1227/00006123-199312000-00006

14. Gonzalez L, Walker M, ... JZ-, 2003 undefined Distinction between paraclinoid and cavernous sinus aneurysms with computed tomographic angiography. academic.oup.com

15. Kim JM, Romano A, Sanan A et al (2000) Microsurgical anatomic features and nomenclature of the paraclinoid region. Neurosurgery 46:670-682. https://doi.org/10.1097/00006123-200003000-00029

16. Lee N, Jung JY, Huh SK et al (2010) Distinction between intradural and extradural aneurysms involving the paraclinoid internal carotid artery with T2-weighted three-dimensional fast spin-echo magnetic resonance imaging. J Korean Neurosurg Soc 47:437441. https://doi.org/10.3340/jkns.2010.47.6.437

17. Thines L, Gauvrit JY, Leclerc X et al (2008) Usefulness of MR imaging for the assessment of nonophthalmic paraclinoid 
aneurysms. Am J Neuroradiol 29:125-129. https://doi.org/10. 3174/ajnr.A0734

18. Thines L, Seon KL, Dehdashti AR et al (2009) Direct imaging of the distal dural ring and paraclinoid internal carotid artery aneurysms with high-resolution T2 turbo-spin echo technique at 3-T magnetic resonance imaging. Neurosurgery 64:1059-1064. https://doi.org/10.1227/01.NEU.0000343523.67272.34

19. Higashida RT, Halbach VV, Dowd C et al (1990) Endovascular detachable balloon embolization therapy of cavernous carotid artery aneurysms: results in 87 cases. J Neurosurg 72:857-863. https://doi.org/10.3171/jns.1990.72.6.0857

20. Thines L, Delmaire C, Le Gars D et al (2006) MRI location of the distal dural ring plane: anatomoradiological study and application to paraclinoid carotid artery aneurysms. Eur Radiol 16:479-488. https://doi.org/10.1007/s00330-005-2879-6

21. Krisht A, Krayenbuhl N, Hafez A, Hernesniemi J (2007) Taming the cavernous sinus: technique of hemostasis using fibrin glue. Skull Base. https://doi.org/10.1055/s-2007-981801

22. Krisht AF, Krayenbühl N, Sercl D et al (2007) Results of microsurgical clipping of 50 high complexity basilar apex aneurysms. Neurosurgery 60:242-250. https://doi.org/10.1227/01.NEU.00002 49265.88203.DF

23. Kupersmith MJ, Hurst R, Berenstein A et al (1992) The benign course of cavernous carotid artery aneurysms. J Neurosurg 77:690-693. https://doi.org/10.3171/jns.1992.77.5.0690

24. Eddleman CS, Hurley MC, Bendok BR, Batjer HH (2009) Cavernous carotid aneurysms: to treat or not to treat? Neurosurg Focus 26:1-20. https://doi.org/10.3171/2009.2.FOCUS0920

25. Hashimoto K, Nozaki K, Hashimoto N (2006) Optic strut as a radiographic landmark in evaluating neck location of a paraclinoid aneurysm. Neurosurgery 59:880-885. https://doi.org/10.1227/01. NEU.0000232664.02190.E1
26. Murayama Y, Sakumura K, Satoh K, Nagahiro S (2001) Identification of the carotid artery dural ring by using three-dimensional computerized tomography angiography. Technical note. J Neurosurg 95:533-536. https://doi.org/10.3171/jns.2001.95.3.0533

27. Obusez EC, Jones SE, Mandell D et al (2019) Feasibility of vessel wall imaging in assessing unruptured paraclinoid aneurysms: clinical observations and preliminary experience. J Clin Neurosci 61:59-65. https://doi.org/10.1016/j.jocn.2018.10.145

28. Tsuboi T, Tokunaga K, Shingo T et al (2007) Differentiation between intradural and extradural locations of juxta-dural ring aneurysms by using contrast-enhanced 3-dimensional time-offlight magnetic resonance angiography. Surg Neurol 67:381-387. https://doi.org/10.1016/j.surneu.2006.08.006

29. Joo W, Funaki T, Yoshioka F, Rhoton AL (2012) Microsurgical anatomy of the carotid cave. Neurosurgery. https://doi.org/10. 1227/NEU.0B013E3182431767

30. Ch L, Cj L, Cf L et al (2016) Comparison of the effectiveness of using the optic strut and tuberculum sellae as radiological landmarks in diagnosing paraclinoid aneurysms with CT angiography. J Neurosurg 125:275-282. https://doi.org/10.3171/2015.7.JNS15 1046

31. Scerbak J, Lapteva O, Sahin OS et al (2020) Identification of the distal dural ring and definition of paraclinoid aneurysms according to bony landmarks on 3-dimensional computed tomography angiography: a cadaveric and radiological study. Oper Neurosurg (Hagerstown, Md) 19(319):329. https://doi.org/10.1093/ONS/ OPZ417

Publisher's note Springer Nature remains neutral with regard to jurisdictional claims in published maps and institutional affiliations. 